\title{
IT Governance in Higher Education Sectors - Teaching Services
}

\author{
Korhan Levent Ertürk, Mohammad Rehan
}

\begin{abstract}
Globally, the teaching services in higher education is under pressure to change and make it more interactive. The governance of higher education sectors has become an important issue from last decade. Now growth $\&$ rapid implementation of Information Technology (IT) is become important part of governance in Higher education sector and become an important issue, how to use IT governance in Teaching services in the university.

IT has become critical in all aspects of universities education system (i.e. teaching, research activities and administration). IT is a tactical component that provides support to all major activities in university, and in the future is set to become an important strategic tool in higher education institutions. This work is analyzing how IT governance can be use or implement in following Teaching Services: (1) Benefits of using ICT in Higher Education, (2) Support studentcentered and self-directed learning, (3) Produce a creative learning environment, (4) Support teaching by facilitating access to course content.
\end{abstract}

Keywords - IT-Governance, Higher Educational, IT Management.

\section{Introduction}

Globally, the higher education is under pressure to change. It is growing exponentially and its contribution to economic success is seen as vital. The higher education institutions are expected to create knowledge; to improve equity; and to timely respond to student needs - and execute more efficiently. The other important reason is impact of IT (information technology) systems on how the institutitution or universities work gets done and how IT affecting all aspects acadmic and business affairs[1][2][3]. They are increasingly competing for students, research activities and funds and academic staff - both with the private \& public sector. In this more complex and comptitive environment direct management is no longer appropriate. So, big question is, how can the governance of higher education institutions assure their dynamism while promoting their key educational, economic and social objectives?

IT services have implications for business and innovation processes and may be a determinant in their evolution. The organization of these services, their status within the organization of the university, and their relationships with other management departments and new technologies is therefore vital [4].

Information Communication Technology (ICT) has become one of the critical issues in all aspects of an university system (i.e. teaching, researching and administration) "Fig. 1". IT is a tactical component that provides support to all important university services at different levels, and in the future is set to become a strategic tool to control an universitiy system.

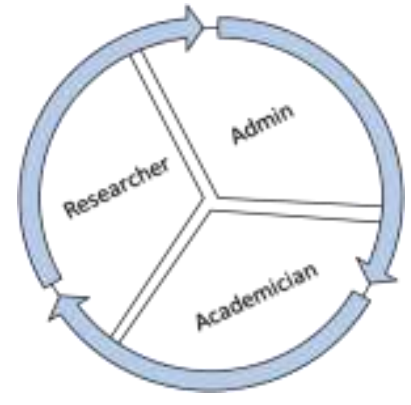

Figure 1. Set of IT Governance in Higher Education

Higher education with its diverse constituencies and its on traditions of institutional governance, has particulary strong stake in the issue of good governance, has a particularly strong stack in the issues of good IT Governance.

\section{IT Governance}

Governance requires a bottom-up participation flow in the governing process and satisfation, and in Electronic governance (e-governance) applications are related to both the usage of technology and citizen participation [1][5]. "Electronic" indicates the technological capacities of our age and "governance" is a new perspective in government paradigm. Innovations in both technology and perspective create new understandings for governing such as "governing with people"[5].

\section{A. Definition}

Information Technology (IT) Governance is senior management's ability to direct, measure and evaluate the use of an enterprise's IT resources in support of the achievement of the organisation's strategic goals [6].

According to CURE [7], IT Governance share some fundamental aspects: (1) IT Governance is the board of directors and executive management's responsibility, (2) The main objective of IT Governance is to align business strategy with IT strategy, (3) IT Governance includes strategies, policies, responsibilities, structures and processes for using IT within an organization, (4) There is a clear difference between IT Governance and IT Management, (5) IT Governance is an integral part of Corporate Governance.

IT Governance pulls the right people together who represent both IT "suppliers" (groups providing IT service to campus) and IT "consumers" (groups receiving value from IT service) to have conversations about balancing [8].

Leadership, organisational structure and processes are used to leverage IT resources to produce the information required and drive the alignment, delivery of value, 
management of risk, optimised use of resources, sustainability and the management of performance.

Strategic objectives must be established and decisions on where, when and how investment in IT is going to take place must be made, in order to achieve the objectives in such a way that competitiveness and effectiveness of the university are improved. Good governance is essential to the effective management and development of an organisation's technology portfolio.

According to Garcia, Vicente and Aragones [4], It is clear that ICTs have become ubiquitous in almost all organizations, institutions and companies, regardless of the sector to which they belong. Hence, effective and efficient ICT management to facilitate optimal results is necessary essential.

\section{B. The Strategic Planning Process Higher Education}

Now ICT is become a force, that has changed several aspects of the life, includes all almost all areas (i.e. medical science, business, travel \& tourism, banking, engineering and designing etc) and the impact of ICT across the past two or three decades has been enormous. It has changed the way of working style in these fields, operate today is vastly different from the ways they operated in the past. But once we looks at education sector, it also has implementation but little slow speed. A number of people have attempted to explore this lack of activity and influence.

Governance in higher education refers to the means by which higher educational institutions are formally organized and managed even there is there some difference of opinion between definitions of management and governance and in university governance system is the way in which universities are operated. Governing structures for higher education are highly differentiated around the world.

$\mathrm{Fu}$ [9] found, the ICT is being applied successfully in instruction, learning, and assessment and considered a powerful tool for educational changes and reforms with an appropriate use of ICT can raise educational quality and connect learning to real-life situations. ICT services for teaching, learning, and knowledge has a life cycle that needs both open-minded nurturing to produce diverse solutions and rigorous management to guide the most promising solutions. Universities needs forward-looking learning environments. Also supported by Oliver[10], there have been a number of factors impeding the wholesale uptake of ICT in education across all sectors with ICT applications provide many options and choices and many institutions are now creating competitive edges for themselves through the choices they are offering students.

IT governance initiatives that include the adoption of control frameworks and good practices to help monitor and improve critical IT activities to increase business value and reduce opeartional problems [2][3][4].

There are several components of ICT usage/implementation in university education system "Fig. 2".

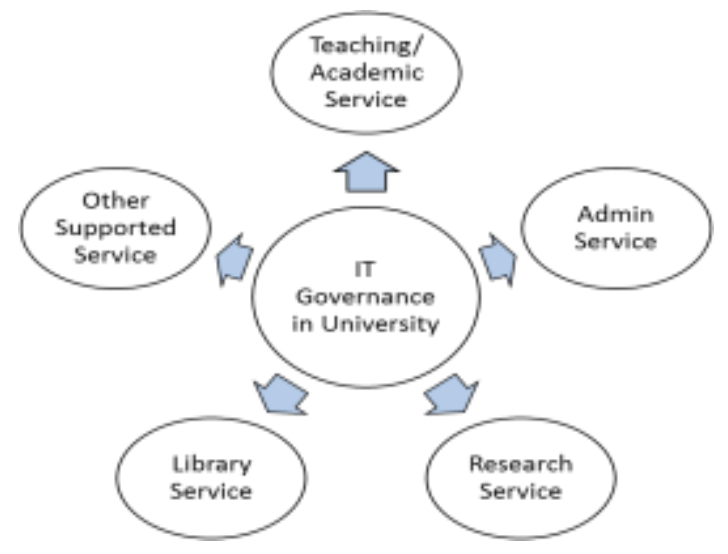

Figure 2. IT Governance in University

\section{Discussion}

In this study we are discussing some following issues of ICT usage in Teaching Services: (1) Benefits of using ICT in education, (2) Support student-centered and self-directed learning, (3) Produce a creative learning environment, (4) Support in teaching services by facilitating access to course content. "Fig. 3".

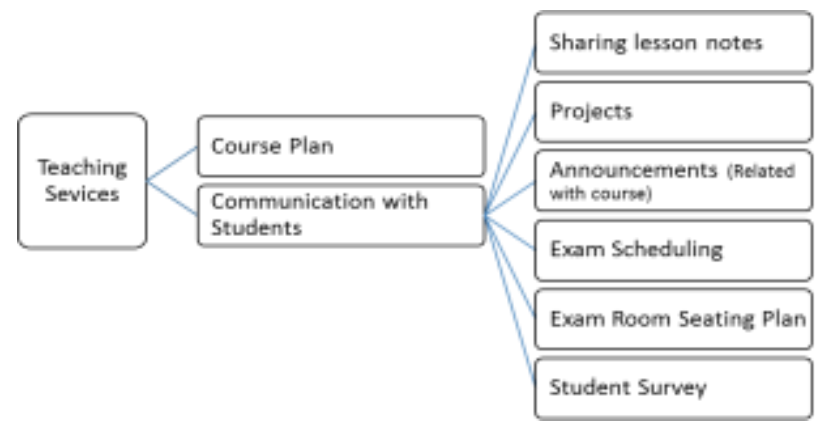

Figure 3. Teaching Services in IT Governance

ICT usage in Teaching Services for students may apply in web portals by means of some software programs "Fig. $4 "$.

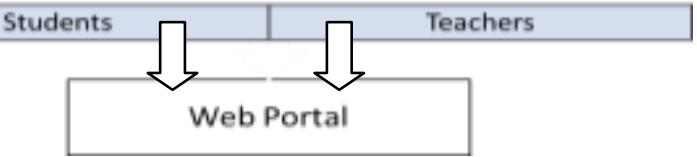

Figure 4. IT Governance System for Students

In the classrom environment, blended learning is a formal education program which combine face-to-face learning with digital instructions by using IT technologies. Learning takes place e-learning, or classroom based environments. There is usually some element of student control over time, place, and/or pace, in combination with in-person classroom or virtual one-on-one instruction. Additionally Adaptive learning is a computer-based and/or online educational system that modifies the presentation of material in response to student performance. Modern learning e-technologies are supporting to make it possible to provide immediate feedback to learners during learning 
activities performed. Learning management systems (LMS) are focused on blended learning, adaptive learning or elearning, and they are used to improve the learning process in universities.

LMS is a software application for the administration, tracking, reporting and delivery of courses. LMS is comprehensive, integrated software that supports the development, delivery, assessment, and administration of courses in blended, or online learning environments, most of the LMSs come with standard or customisable features. The most widely cited reason according to the LMS research was functionality, with price a close second, and support a distant third and LMS enable communications between students, teachers and the other players (tutors, administraton personel etc.) by extend learning, any time, anywhere on any device or cloud. Some LMSs can deliver content and allow students to access via mobile devices. Although many LMS vendors use mobility as a key selling point for their software, the majority of respondents in our sample access their LMS from a desktop computer (89 percent) or laptop (76 percent). Only 25 percent of users access LMS from tablets while, 19 percent use smartphones. Advanced LMSs evolve, they're increasingly moving to the cloud. This allows for better functionality and mobility, enhanced security and lower costs. Technical service personel can assess the reliability/stability, scalability, and security of the LMS [11][12][13][14].

Additionally, LMS in the literature is perhaps most commonly associated with computer applications which we must identify as Course Management Systems (CMS). These systems can be used primarily for online or blended learning, supporting the shariring course materials online, with students and other supporting staff, tracking student performance, storing student submissions, student satisfaction survey, and communication between the students with their teacher \& course supporting staff. Some of this same functionality can be seen within LMSs as well, so it is understandable why confusion might exist about the differences between the two types of systems. By contrast, a learning content management system (LCMS) is a related software technology that provides a multi-user environment where developers, authors, instructional designers, and subject matter experts may create, store, reuse, manage, and deliver digital educational technology (also known as elearning) content from a central object repository. LCMS focuses on the development, management and publishing of the content that will typically be delivered via an LMS. Users can both create and re-use content and reduce duplicated development efforts [15][16][17].

Whenever teachers plan or design their study plan for any specific course(s), they are in essence making a series of decisions aimed at creating a design, which in this case consists of a plan of activities and responsibilities of teacher and students, will do in that course. Developing a course plan in the context of the content, both broad and specific, means thinking not only about having students learning content but also about how to give students practical (or industrial know-how in some specific courses) knowledge that are important in the course goals. A course plan includes not only the goals and the content topics, but also teaching method/process and what the students will do during the lesson. In order to achieve end-of-semester goals, if any kind of help needed by students, they use the system.
If goals focus solely on mastery of content, then practice in reiterating and explaining what students have learned is appropriate. Many courses do this. During course, demonstration of achievement of these content mastery goals typically involves a series of midterm and final exams focused largely on basic order thinking skills such as identifying, listing, explaining, describing, summarizing, and so on.

The teachers can create and upload study materials (lesson notes, projects) in LMS, and then extend their content by sharing and making it allow to students, other tutors, groups and may link or share with other course(s). The LMS contains course assembly tools as well as features to create tests, quizzes, homework, lab exercises, exams and surveys. The purpose of the exams may be to improve the effectiveness of course content and student progress tracking. Any question type (including multiple choice, fill in the blank, short answer, matching and calculated numeric) may be used in any combination to generate exams and surveys. Exams and surveys may contain questions drawn at random from question pools, enabling a single test to be delivered multiple times to students throughout semester with students receiving different questions each time [13][18][19][20][21].

The assessment and grading of homework and course projects can be done by the LMS platform. LMS automate several aspects of the whole procedure, like automatically accepting student submissions (through file upload), cataloguing and presenting them to the teacher, providing grade entry forms and storing the students' grades alongside those automatically calculated by the LMS. The top mostused LMS include assessment and testing tools, blended learning, and student portal functionality. People's motivations for buying an LMS were varied [18][19][20][21].

Meanwhile, classrooms can be assigned for series of midterm and final exams and then students can be allocated seats in these rooms. The seating plans for rooms, that are to be used may be set up. Exam rooms can be used for more than one exam at a time. Any seats used by students will be marked with a student icon etc. with a LMS customized tool "Fig. 5".

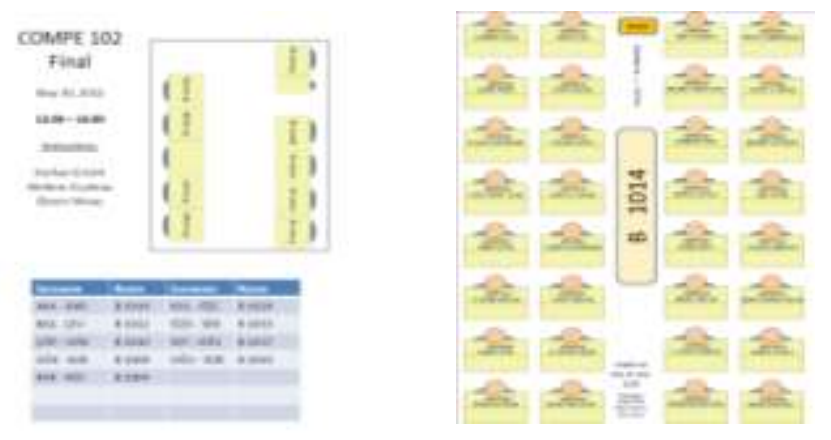

Figure 5. Exam Room Seating Plan (this work has been done by authors)

On the other hand there are some standard social networks applications, which are providing features such as interaction, active collaboration learning, resource sharing, which are the important features of learning. LMSs provide a limited personalized learning environment to students and most of them have lack of social communication tools, and they don't have as much capabilities as social networking 
web-portals. E-learning tools for social networks will be developed and social networks' features will be integrated to current LMS. By this way information sharing and collaboration capabilities of the social networks will promote the LMSs and a blended and adaptive learning environment will be developed. As with any tool, LMS software must be carefully selected, implemented and utilized to yield positive results [22][23][24]. MarketsandMarkets expects the total Learning Management Systems market to grow from USD 4.07 Billion in 2015 to USD 11.34 Billion by 2020 at a Compound Annual Growth Rate (CAGR) of $22.8 \%$ during the forecast period [25].

\section{Conclusion}

IT governance implementation \& usage in a university system is an important issues. We are trying to find out the way of usage an IT Governance system. In LMS system (in genral) we are focuing communication with students and provide support in teaching process, which is included sharing \& controlling study resources, paritally help in examination conducting process(i.e. students seating arrangements etc, fig. 5).

One of the important objective of this system is to save time (by developing some IT solutions and used them in teaching \& learning process), with effective communication among all stackholder. LCMS will also support to provide effective and intractive learning environment among users.

For future research there is big scope of IT governance, to contribute in conducting examination \& grading procees (i.e. exams, assignments, projects etc) with improved \& quick communications. Most importantly how teaching process can be improved to attarct students.

\section{References}

[1] Ribeiro J. and Gomes R. "IT Governance using COBIT implemented in a High Public Educational Institution - A Case Study", Computing and Computational Intelligence, ISBN: 978-960-474-088-8, 2009.

[2] Chen G., "IT Service System Design and Management of Educational Information System", The 1st International Conference on Information Science and Engineering, 2009.

[3] Grant G. B., and Anderson G.,"Customer Relationship Management A Vision for Higher Education", Chapter 3, Web Portals and Higher Education, Published by Jossey-Bass, A Wiley Company. Reprinted by permission of John Wiley \& Sons, Inc, 2002.

[4] García V.V., Vicente E. J. F. and Aragonés L. U.,"Maturity Model for IT Service Outsourcing in Higher Education", International Journal of Advanced Computer Science and Applications, Vol. 4, No. 10., 2013.

[5] Öktem M. K., Demirhan K. and Demirhan H. "The Usage of EGovernance Applications by Higher Education Students", Educational Sciences: Theory \& Practice, 14(5) • 1925-1943., 2014.

[6] Corporate Governance of IT, "COBIT 5 Foundation, Implementation, Assessment and IT Governance", Retrieved from $\mathrm{http} / / /$ itgovernance.com/00/index.php?option=com_content\&view= article\&id=27: governance\&catid=1:latest\&Itemid=2, 2011 .

[7] CURE, "Governance of information technology in higher education", Retrieved from http://www.crue.org/export/sites/Crue/Publicaciones /Documentos/GobiernoTI/FolletoITGovernance.pdf, 2009.

[8] Borwick, J., "What's IT governance?" Retrieved from http://www.heitmanagement .com/blog/2013/05/whats-it-governance, 2013.
[9] Fu., J.S., "ICT in Education: A Critical Literature Review and Its Implications, International Journal of Education and Development using Information and Communication Technology" (IJEDICT), 2013, Vol. 9, Issue 1, pp. 112-125

[10] Oliver R.,'"The role of ICT in higher education for the 21st century: ICT as a change agent for education," Proceedings of the Higher Education for the 21st Century Conference, Curtin, 2003.

[11] Curtin E. and Ryann K., "Field Guide to Learning Management Systems", ASTD Learning Circuits, 2009.

[12] Bora, U.J. and Ahmet, M., "E-Learning using Cloud Computing", International Journal of Science and Modern Engineering (IJISME) ISSN: 2319-6386, Volume-1, Issue-2, January 2013.

[13] SoftwareAdvice, "Learning Management Systems, UserView" Retrieved from http://www.softwareadvice.com/, 2015.

[14] Haag, J., "From eLearning to mLearning: The Effectiveness of Mobile Course Delivery", Interservice/Industry Training, Simulation, and Education Conference (I/ITSEC) 2011.

[15] Kerschenbaum, S. LMS Selection Best Practices. Adayana Chief Technology Officer. pp. 1-15, 2009.

[16] SEO Tech Experts, "Content Management System". Retrieved from http://www.seotechexperts.com/blogs/content-managementsystem.html.,2015.

[17] Boag, P. "10 Things To Consider When Choosing The Perfect CMS". Smashing Magazine. Retrieved from http://www.smashingmagazine.com/2009/03/10-things-to-considerwhen-choosing-the-perfect-cms/, 2015.

[18] Hsiu-Ping Y. and Shihkuan H.,'Designing a learning management system to support instruction", ACM DL.,Volume 51 Issue 4, April 2008 .

[19] Wright, C.R., Lopes, V., Montgomene, I.C., Reju. S., Schmoller, S., "Selecting a Learning Management System: Advice from an Academic Perspective", EDUCAUSE Articles Retrieved from http://er.educause.edu/articles/2014/4/selecting-a-learningmanagement-system-advice-from-an-academic-perspective, 2014.

[20] E-Learning Industry, "Learning Management Systems Comparison Checklist of Features", Retrieved from http://elearningindustry.com/learning-management-systemscomparison-checklist-of-features, 2015.

[21] Stone, D. and Zheng G. "Learning Management Systems in a Changing Environment", Handbook of Research on Education and Technology in a Changing Society, Chapter: 56, IGI Global, 2014.

[22] Course Networking,"We are EdTech and Social", Retrieved from https://www.thecn.com/whycn, 2015.

[23] Hrastinski, S. and Aghaee, N. ,"How are campus students using social media to support their studies? An explorative interview study, Educ Inf Technol, 17:451-464., 2012

[24] Talented e-Learning,"Social Learning - How Social is Your LMS?" Retrieved from http://talentedlearning.com/social-learning-social-lms, 2014.

[25] MarketsandMarkets, "Learning Management System (LMS) Market". Retrieved from http://www.marketsandmarkets.com, 2015.

About Authors:

K. L. Ertürk and M. Rehan are with the Department of Information Systems Engineering, Faculty of Engineering, Atilim University, 06836, Ankara, Turkey 